\title{
Sleep Deprivation Impairs the Human Central and Peripheral Nervous System Discrimination of Social Threat
}

\author{
(D)Andrea N. Goldstein-Piekarski, ${ }^{1,2}$ Stephanie M. Greer, ${ }^{1}$ Jared M. Saletin, ${ }^{2}$ and Matthew P. Walker ${ }^{1,2}$ \\ ${ }^{1}$ Helen Wills Neuroscience Institute and ${ }^{2}$ Department of Psychology, University of California, Berkeley, California 94720
}

Facial expressions represent one of the most salient cues in our environment. They communicate the affective state and intent of an individual and, if interpreted correctly, adaptively influence the behavior of others in return. Processing of such affective stimuli is known to require reciprocal signaling between central viscerosensory brain regions and peripheral-autonomic body systems, culminating in accurate emotion discrimination. Despite emerging links between sleep and affective regulation, the impact of sleep loss on the discrimination of complex social emotions within and between the CNS and PNS remains unknown. Here, we demonstrate in humans that sleep deprivation impairs both viscerosensory brain (anterior insula, anterior cingulate cortex, amygdala) and autonomic-cardiac discrimination of threatening from affiliative facial cues. Moreover, sleep deprivation significantly degrades the normally reciprocal associations between these central and peripheral emotion-signaling systems, most prominent at the level of cardiac-amygdala coupling. In addition, REM sleep physiology across the sleep-rested night significantly predicts the next-day success of emotional discrimination within this viscerosensory network across individuals, suggesting a role for REM sleep in affective brain recalibration. Together, these findings establish that sleep deprivation compromises the faithful signaling of, and the "embodied" reciprocity between, viscerosensory brain and peripheral autonomic body processing of complex social signals. Such impairments hold ecological relevance in professional contexts in which the need for accurate interpretation of social cues is paramount yet insufficient sleep is pervasive.

Key words: amygdala; anterior cingulate cortex; anterior insula; emotion; sleep deprivation; social threat

\section{Introduction}

Facial expressions provide some of the most significant social and emotional signals in our environment, the accurate interpretation of which determines survival-related behavior (Adolphs et al., 1998; Oosterhof and Todorov, 2008). Such cues vary not only in intensity, from nonemotional to emotional, but can also traverse a range of different emotions. Therefore, beyond the basic recognition of an emotion, optimal interpretation of affective expressions critically requires accurate discrimination between emotions. Arguably one of the most adaptive examples is the need to disambiguate threatening facial signals from affiliative, nonthreatening expressions. Failing to discern between such cues leads to significant social dysfunction and survival risk caused by nonoptimal decisions and consequential actions (Adolphs et al., 1998; Oosterhof and Todorov, 2008).

Successful discrimination of affective stimuli is supported both by the CNS, notably viscerosensory cortical brain regions of

\footnotetext{
Received Dec. 21, 2014; revised May 12, 2015; accepted May 28, 2015.

Author contributions: A.N.G.-P.,S.M.G., and M.P.W. designed research;A.N.G.-P. and S.M.G. performed research; J.M.S. contributed unpublished reagents/analytic tools; A.N.G.-P. analyzed data; A.N.G.-P. and M.P.W. wrote the paper.

This work was supported by the National Institutes of Health Grants R01AG031164, R01MH093537, and R21DA031939 to M.P.W. and Grant F31MH094075 to A.N.G. We thank Matthew Brett for helpful advice on fMRI analyses and the following research assistants involved in the study: Kelsey Hudson, Linda Nix, Graham Cooper, Aubrianna Zhu, Jamie Sallee, Sarah Roth, JeffWayland, Alex Beagle, Mana Kahali, Anna Akullian, Brian Johnson, and Roupen Khanjian.

The authors declare no competing financial interests.

Correspondence should be addressed to Matthew P. Walker, Department of Psychology, 3331 Tolman Hall, University of California, Berkeley, CA 94720-1650. E-mail: mpwalker@berkeley.edu.

DOI:10.1523/JNEUROSCI.5254-14.2015

Copyright $\odot 2015$ the authors $\quad 0270-6474 / 15 / 3510135-11 \$ 15.00 / 0$
}

the anterior insula and anterior cingulate, together with subcortical amygdala (Blasi et al., 2009; Fan et al., 2011), and the PNS, including rapid, autonomic-mediated changes in heart rate (van Honk et al., 2001; Critchley, 2005). Importantly, these affectevoked PNS and CNS responses do not simply co-occur. Instead, they are causally interconnected in an afferent-efferent loop (Critchley, 2005; Dalton et al., 2005; Gray et al., 2012), reflecting a reciprocity consistent with theories of "embodied" emotion processing (James, 1894; Craig, 2002; Critchley and Harrison, 2013).

One factor increasingly linked to emotional brain dysregulation is insufficient sleep. A lack of sleep significantly amplifies amygdala reactivity to emotional stimuli (Yoo et al., 2007; Goldstein et al., 2013), whereas the presence of sleep, and specifically REM sleep, beneficially depotentiates amygdala reactivity in response to previous emotional experiences (van der Helm et al., 2011). Moreover, sleep deprivation impairs the basic ability to recognize emotional from nonemotional face stimuli (Pallesen et al., 2004; van der Helm et al., 2010; Cote et al., 2014; Maccari et al., 2014). Further, this altered behavior has been associated with nonspecific (and larger) event-related potentials in response to faces regardless of emotion (Cote et al., 2014).

Despite emerging links between sleep and affective brain function, the impact of sleep and sleep deprivation on the interconnected central brain and peripheral autonomic discrimination of complex social emotions remains unknown. Targeting these issues, we sought to test two complimentary hypotheses: (1) that sleep deprivation impairs the embodied CNS (brain) and PNS 
A

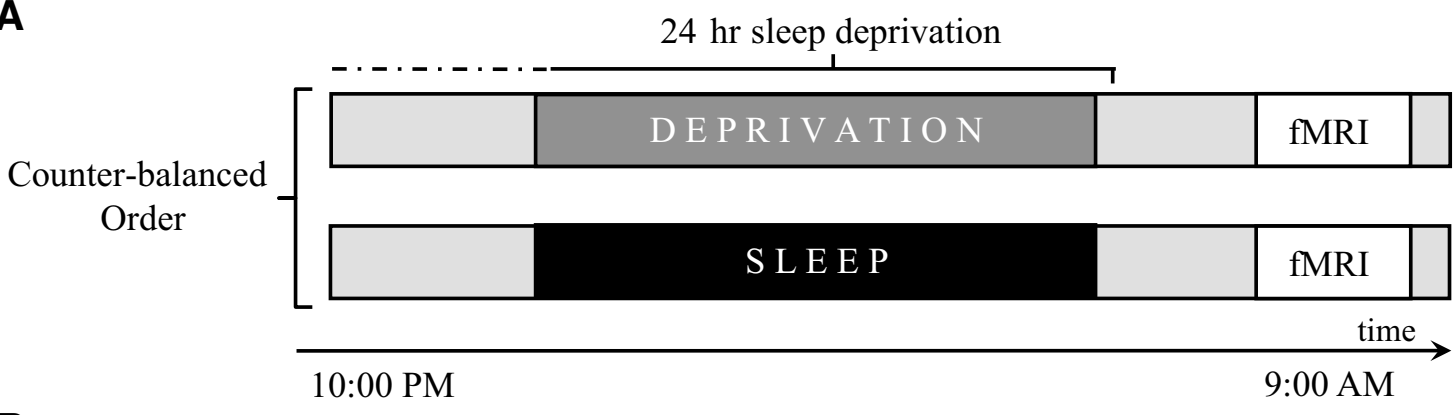

B

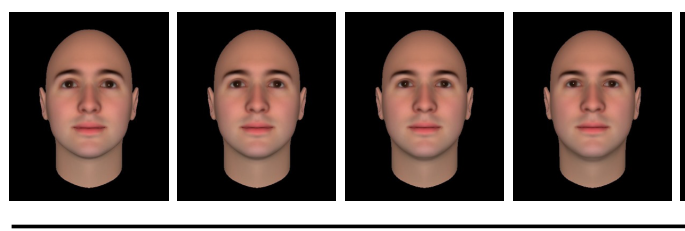

Not Threatening

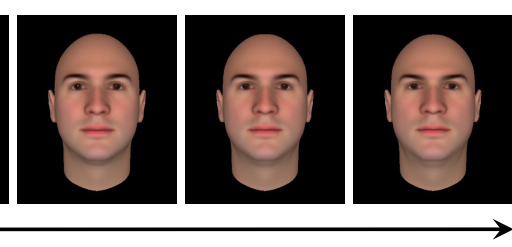

Threatening

C

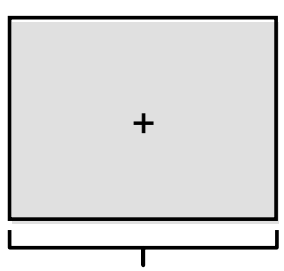

Average

$1800 \mathrm{~ms}$

[1300ms $-2300 \mathrm{~ms}]$

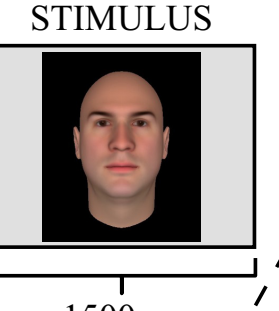

$1500 \mathrm{~ms}$

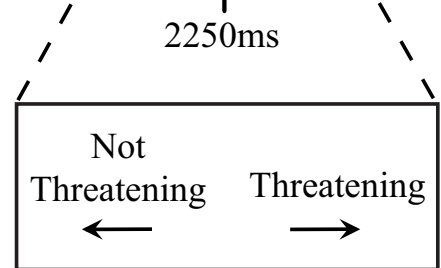

Figure 1. Study design. $\boldsymbol{A}$, Time course of experiment for both the sleep-deprived and sleep-rested conditions. $\boldsymbol{B}$, Example of the emotional face stimuli gradient ranging from not threatening to increasingly threatening. $\boldsymbol{C}$, Schematic for the threat discrimination fMRI task. Each trial lasted an average of $5.75 \mathrm{~s}$. Trials began with a brief fixation screen that was presented using a variable jittered duration time for optimal signal estimation (maximum $=2.3 \mathrm{~s}$, minimum $=1.3 \mathrm{~s}$, mean $=1.8 \mathrm{~s}$; Dale, 1999). After the fixation cross, each trial proceeded with a $1.5 \mathrm{sface} \mathrm{stimulus} \mathrm{followed}$ by a 2.25 s response period in which participants were asked to classify the prior face as either "threatening" or "not threatening." Pseudorandomly interspersed between these threat trials were null trial events (data not shown) in which a fixation point was displayed on the screen for a jittered duration (maximum $=5 \mathrm{~s}$, minimum $=1.5 \mathrm{~s}$, mean $=2.5 \mathrm{~s}$ ), serving as a baseline condition and modulating intertrial interval variability for optimal modeling of trial events.

(cardiac) mechanisms supporting the discrimination of threatening from affiliative (safe, nonthreatening) facial signals relative to a full night of sleep and (2) that REM sleep physiology on the sleep-rested night significantly explains next-day interindividual differences in the discrimination accuracy of both of these nervous system responses. Within the PNS, hypotheses focused a priori on the stimulus-evoked cardiac response, a reliable measure of threat discrimination (van Honk et al., 2001). Within the CNS, analyses targeted regions of interest (ROIs) within the viscerosensory network of the dorsal anterior cingulate cortex (dACC), anterior insula, and amygdala that collectively supports affective face processing and modulates autonomic evoked heart rate changes (Critchley, 2005; Gray et al., 2012).

\section{Materials and Methods}

Participants. Eighteen healthy adults, age 18-30 years (mean: $19.6 \pm 1.45$ $\mathrm{SD}, 9$ female) completed a repeated-measures crossover design (described below). Participants abstained from caffeine and alcohol for the $72 \mathrm{~h}$ before and during the entire course of the study and kept a normal sleep-wake rhythm (7-9 h of sleep per night with sleep onset before 1:00 $\mathrm{h}$ in the morning and rise time no later than 9:00 $\mathrm{h}$ ) for the 3 nights before the study participation, as verified by sleep logs. Exclusion criteria, assessed using a prescreening semistructured interview were as follows: a history of sleep disorders, neurologic disorders, open and closed head injury, Axis I psychiatric disorders according to the DSM-IV-TR criteria (encompassing mental disorders including depression, anxiety disorders, bipolar disorder, attention deficit disorder, and schizophrenia), history of drug abuse, and current use of antidepressants, psychostimulants, or hypnotic medications. Subjects who reported drinking three or more caffeine-containing beverages per day such as caffeinated coffee, tea, or soft drinks were excluded. The study was approved by the local human ethics studies committee, with all participants providing written informed consent.

Experimental design. After screening, participants entered the repeated-measures study design (Fig. 1A), performing an emotional face discrimination task (described below) inside of the fMRI scanner. This occurred once after a night of sleep and once after $24 \mathrm{~h}$ of total sleep deprivation. In the sleep-deprived session, participants arrived at the laboratory at 9:00 P.M. Thereafter, they were monitored continuously throughout the enforced waking period by trained personnel, independently confirmed using actigraphy monitoring (an accepted device used 
Table 1. Polysomnography sleep-stage values for the sleep rested session (mean \pm SD)

\begin{tabular}{lrcc}
\hline & Sleep time $(\mathrm{min})$ & \% Total sleep time & $\begin{array}{l}\text { Obtained by \% } \\
\text { of participants }\end{array}$ \\
\hline Total sleep time & $469.43 \pm 38.7$ & & \\
Stage 1 & $25.72 \pm 10.4$ & $5.53 \pm 2.4$ & $100 \%$ \\
Stage 2 & $253.15 \pm 34.1$ & $53.87 \pm 5.2$ & $100 \%$ \\
SWS & $90.35 \pm 28.4$ & $19.41 \pm 6.7$ & $100 \%$ \\
REM & $100.20 \pm 24.8$ & $21.20 \pm 4.3$ & $100 \%$ \\
\hline
\end{tabular}

SWS, NREM stage 3 and 4.

to identify periods of sleep and wake; Actiwatch2; Philips). EEG data were not acquired during the sleep deprivation session. Activities during the sleep deprivation period were limited to use of the Internet, E-mail, short walks, reading, movies of low emotionality, and playing board games, providing a standardized regiment of waking activity without undue stress. The following morning at $\sim 8: 30$ A.M. ( $\pm 90 \mathrm{~min}$ ), participants performed the emotional face recognition task in the fMRI scanner.

In the sleep-rested session, participants came to the laboratory at 8:00 P.M. and were prepared for an $\sim 8 \mathrm{~h}$ in-bed polysomnographic (PSG) night of sleep recording in the laboratory (11:00 P.M.-7:30 A.M. \pm 30 min; details below). At 9:00 A.M., at least $1 \mathrm{~h}$ after awakening, participants performed an alternate version of the emotional face discrimination task in the fMRI scanner. Test sessions were separated by at least $6 \mathrm{~d}$ (mean, 12.42), with the order of the sleep-rested and sleep-deprived sessions counterbalanced across subjects.

To assess the degree of difference between the structured sleep schedule of the experiment and each participant's unrestricted sleep schedule, subjects completed the Pittsburgh Sleep Quality Index upon study entry. This instrument contains questions relating to the bed time, rise time, and duration of sleep episodes across the past month (Buysse et al., 1989). In addition, to characterize recent sleep status, participants further completed sleep logs $5 \mathrm{~d}$ before each experimental session. Participants conformed to the structured sleep schedule during the month before the experiment, including across the $5 \mathrm{~d}$ before the experimental session. Specifically, in the month leading up to the study, participants reported average bed times of 12:13 A.M. ( $\pm 50 \mathrm{~min} S \mathrm{~S})$, average rise times of 8:00 A.M. ( $\pm 62 \mathrm{~min} S D)$, and average sleep duration of $7.53 \mathrm{~h}( \pm 0.76 \mathrm{~h} \mathrm{SD})$. Similarly, for the $2 \mathrm{~d}$ before the start of the structured sleep schedule, participants reported sleep-log mean bed times of 12:21 A.M. ( $\pm 45 \mathrm{~min}$ $\mathrm{SD})$, mean rise times of 7:53 A.M. ( $\pm 42 \mathrm{~min} \mathrm{SD}$ ), and mean sleep durations of $7.53 \mathrm{~h}( \pm 0.52 \mathrm{~h} \mathrm{SD})$. Such findings suggest that the participants' normative schedules were congruent with the study requirements. Although subjective sleep logs are used regularly to verify compliance to required preexperimental sleep schedules, they are less accurate than objective measures such as actigraphy. It is therefore possible that participants were entering one or both conditions with some degree of sleep dept. In addition, the lack of a first habituation night in the sleep laboratory before the experimental session may have resulted in poorer sleep quality during the sleep-rested night (Agnew et al., 1966; Kingshott and Douglas, 2000). Nevertheless, four aspects of empirical data suggest that participants were similarly rested at the time of entering both conditions, as well as on the morning of the sleep-rested session: (1) the duration and sleep-stage amounts measured with objective PSG on the rested night conform well to age and population norms (Table 1; Ohayon et al., 2004); (2) participants additionally endorsed a high degree of functioning and concentration on standardized measures of subjective alertness (Hoddes et al., 1973) on the evening before both experimental manipulations (mean: $2.26 \pm 1.02 \mathrm{SD}$ for the start of the sleep deprivation session; mean: $2.89 \pm 1.11 \mathrm{SD}$ for the start of the sleep-rested session), and the morning of the sleep-rested test session (mean: $2.19 \pm 0.93 \mathrm{SD}$ ); (3) subjective alertness did not differ significantly on the evenings of both conditions before sleep/sleep deprivation $(t=1.70, p>0.11)$; and (4) verifying our condition manipulation, the night of sleep deprivation resulted in a significant decrease in next-day alertness ratings (mean: $4.50 \pm 1.34 \mathrm{SD}$ for the morning of the $\mathrm{SD}$ condition) relative to the morning of the sleep-rested condition assessed at equivalent times of day $(t=10.22, p<0.001)$.

fMRI emotional face discrimination task. Each subject was administered two versions of a the fMRI emotional face discrimination task (Said et al., 2009; Said et al., 2010) counterbalanced across sleep-rested and sleepdeprived fMRI sessions. Two sets of 70 faces (one set for each task version) were selected from a published database of computer-generated face stimuli designed to range in a gradient from threatening to affiliative, nonthreatening across several identities (Oosterhof and Todorov, 2008). Specifically, 10 Caucasian face identities were generated for each set using the FaceGen Modeler program version 3.1 (http://facegen.com). Each face identity was then morphed using a threat computer model (Oosterhof and Todorov, 2008) to create seven versions of each identity that ranged from not threatening to increasingly threatening (Fig. 1B).

Each of the 70 threat-discrimination trials consisted of a $1.5 \mathrm{~s}$ face stimulus presentation, followed by a response screen instructing participants to classify the face in a binary judgment as either "threatening" or "not threatening" (see Fig. $1 C$ for trial timing and structure). Trials were pseudorandomly shuffled so that no face identity or threat level would be presented more than two times in a row. Further, 30 null trial events were pseudorandomly interspersed between face trials, during which a fixation point was displayed on the screen for a jittered duration (maximum $=5 \mathrm{~s}$, minimum $=1.5 \mathrm{~s}$, mean $=2.5 \mathrm{~s}$ ). This allowed for intertrial variability that is optimal for event-related fMRI design (Dale, 1999).

Behavioral data analysis. A discrimination index was calculated by subtracting the difference in the proportion of faces that participants classified as "threatening" from the proportion of faces that participants classified as "not threatening." A zero value would represent equal numbers of faces classified as threatening and not threatening, whereas a negative number would represent more images being classified as not threatening than threatening. Comparisons of behavioral discrimination indices between rested and deprived conditions were performed using two-tailed, paired $t$ tests. Behavioral data analyses were performed using STATA 11 (StataCorp), with $p<0.05$ considered significant.

$f M R I$ acquisition. BOLD contrast functional images were acquired with echoplanar $\mathrm{T}^{*}$-weighted imaging using a Siemens 3 tesla MRI scanner with a 12-channel head coil. Each image volume consisted of 32 ascending $3.5 \mathrm{~mm}$ slices $(96 \times 96$ matrix; $\mathrm{TR}=2000 \mathrm{~ms}$; $\mathrm{TE}=28 \mathrm{~ms}$; size $2.5 \times 2.5 \times 3.5 \mathrm{~mm}$, FOV $224 \mathrm{~mm}$, flip angle $\left.=90^{\circ}\right)$. A high-resolution T1-weighted structural scan was acquired at the end of the sleep-rested session $\left(256 \times 256\right.$ matrix; $\mathrm{TR}=1900 ; \mathrm{TE}=2.52$; flip angle $=9^{\circ} ; \mathrm{FOV}$ $256 \mathrm{~mm} ; 1 \times 1 \times 1 \mathrm{~mm}$ ). Concurrent eye tracking was used to further verify wakefulness during both test sessions (ViewPoint Eye Tracker; Arrington Research). Heart rate was monitored throughout the fMRI task using a pulse oximeter (8600FO; Nonin Medical) placed on the left index finger.

fMRI analysis. Preprocessing and data analysis were performed using Statistical Parametric Mapping software implemented in MATLAB (SPM8; Wellcome Department of Cognitive Neurology, London). Images were motion corrected and slice scan time corrected and then spatially normalized to the Montreal Neurological Institute template and smoothed using an $8 \mathrm{~mm}$ full-width-at-half-maximum Gaussian kernel using default parameters in SPM8. For each subject, trial-related activity was assessed by convolving a vector of trial onsets with a canonical hemodynamic response function. The six movement-related covariates (three rigid-body translations and three rotations determined from the realignment preprocessing step) were used as regressors in the design matrix for modeling movement-related artifact in the time series. In addition, a white matter regressor was included to control for physiological noise. Nonsphericity of the error covariance was accommodated for using a first-order autoregressive (AR1) model in which the temporal autocorrelation was estimated by pooling over suprathresholds (Friston et al., 2002).

A general linear model (Friston et al., 1994) was specified for each participant to investigate the effects of interest. Contrasts were created at the first (individual) level with three events: faces classified as threatening, faces classified as not threatening, and null events. The experimental hypotheses were tested at the second (group) level using two complimentary accepted ROI approaches (Poldrack and Mumford, 2009). First, to 
Table 2. Voxelwise whole-brain results for the sleep-rested condition

\begin{tabular}{|c|c|c|c|c|c|}
\hline Region (BA) & $\begin{array}{l}\text { Cluster size } \\
\left(\mathrm{mm}^{3}\right)\end{array}$ & $x$ & $y$ & $z$ & $\begin{array}{l}\text { Peak } \\
\text { Zscore }\end{array}$ \\
\hline \multicolumn{6}{|l|}{ Sleep-rested threatening $>$ not threatening } \\
\hline Inferior frontal gyrus (BA 47)-L & 45369 & -38 & 20 & -10 & 5.95 \\
\hline Inferior frontal gyrus (BA 47)-L & & -48 & 20 & 0 & 5.6 \\
\hline Middle frontal gyrus (BA 47)-L & & -50 & 38 & -4 & 4.16 \\
\hline Inferior frontal gyrus (BA 47)- $R$ & 29422 & 42 & 26 & -8 & 5.21 \\
\hline Inferior frontal gyrus (BA 47)- $R$ & & 40 & 20 & -14 & 4.87 \\
\hline Inferior frontal gyrus (BA 47)- $R$ & & 32 & 22 & -8 & 4.85 \\
\hline Superior frontal gyrus (BA 8)-L & 33556 & -6 & 24 & 56 & 4.84 \\
\hline Medial frontal gyrus (BA 8)-L & & -6 & 24 & 46 & 4.42 \\
\hline Medial frontal gyrus (BA 9)-L & & -2 & 40 & 32 & 4.05 \\
\hline Lateral globus pallidus-L & 284 & -18 & -2 & -12 & 3.5 \\
\hline Superior temporal gyrus (BA 22)-R & 416 & 48 & -30 & -2 & 3.38 \\
\hline Middle frontal gyrus (BA 6)-R & 306 & 42 & 0 & 60 & 3.37 \\
\hline \multicolumn{6}{|l|}{ Sleep-rested not threatening $>$ threatening } \\
\hline Medial frontal gyrus (BA 10)-L & 14788 & -6 & 50 & -8 & 4.72 \\
\hline Anterior cingulate (BA 32)-R & & 8 & 36 & -10 & 3.91 \\
\hline Medial frontal gyrus (BA 10)-R & & 12 & 52 & -6 & 3.85 \\
\hline Middle frontal gyrus (BA 9)-R & 12141 & 26 & 24 & 36 & 4.66 \\
\hline Superior frontal gyrus (BA 6)-R & & 22 & 12 & 52 & 3.97 \\
\hline Precuneus (BA 19)-L & 4878 & -38 & -76 & 34 & 4.19 \\
\hline Superior frontal gyrus (BA 8)-L & 4900 & -24 & 14 & 54 & 3.77 \\
\hline Middle frontal gyrus (BA 8)-L & & -22 & 26 & 38 & 3.66 \\
\hline Middle frontal gyrus (BA 8)-L & & -22 & 22 & 46 & 3.55 \\
\hline Precuneus (BA 7)-R & 6234 & 4 & -52 & 52 & 3.76 \\
\hline Precuneus (BA 7)-R & & 0 & -48 & 46 & 3.56 \\
\hline Superior temporal gyrus (BA 22)-L & 1094 & -56 & -6 & -4 & 3.73 \\
\hline Precentral gyrus (BA 6)-L & 3063 & -44 & -12 & 34 & 3.69 \\
\hline Insula (BA 13)-L & & -42 & -14 & 22 & 3.5 \\
\hline Cingulate gyrus (BA 31)- $R$ & 2253 & 14 & -36 & 40 & 3.65 \\
\hline Subcallosal gyrus (BA 25)-R & 744 & 6 & 20 & -14 & 3.58 \\
\hline Superior temporal gyrus (BA 22)- $R$ & 634 & 58 & 0 & -4 & 3.31 \\
\hline Inferior parietal lobule (BA 40)-L & 153 & -68 & -32 & 32 & 3.26 \\
\hline Insula (BA 13)-R & 88 & 38 & -12 & 20 & 3.23 \\
\hline Precentral gyrus (BA 6)- $R$ & 263 & 46 & -8 & 38 & 3.23 \\
\hline Cingulate gyrus (BA 31)-L & 153 & -10 & -32 & 44 & 3.19 \\
\hline Postcentral gyrus (BA 3)-L & 44 & -16 & -42 & 66 & 3.14 \\
\hline Middle temporal gyrus (BA 21)-L & 22 & -66 & -10 & -8 & 3.09 \\
\hline Caudate head-L & 22 & -16 & 26 & 8 & 3.09 \\
\hline
\end{tabular}

Uncorrected $p<0.001,>10 \mathrm{~mm}^{3}$ contiguous cluster extent.

characterize the impact of sleep deprivation on the viscerosensory regions, average parameter estimates were extracted from each ROI volume independently and entered into a repeated measure condition (sleep-rested, sleep-deprived) $\times$ threat classification (threatening, not threatening) ANOVA performed in STATA 11 (StataCorp). Main effects and interactions were tested using a significance of $p<0.05$. To further visualize these effects within the areas of interest, a second method used the voxelwise approach (Poldrack and Mumford, 2009). This method reports significant differences only from significant voxels within each ROI using a familywise error (FWE) correction thresholded at $p<0.05$. Differences were examined using a repeated-measures condition (sleeprested, sleep-deprived) $\times$ threat classification (threatening, not threatening) ANOVA implemented in SPM8. All $F, t$, and $p$-values are presented using the average ROI-based approach, whereas the overlay of activation maps on anatomical templates uses the voxelwise analysis. Because this is the first imaging study to examine the neural impact of sleep deprivation on social threat discrimination, we additionally describe effects outside of our a priori ROIs at the whole-brain level. However, these are reported for descriptive purposes only (Tables 2, 3; whole-brain voxelwise ANOVA analyses, thresholded at $p<0.001$, uncorrected) and are not discussed further.

The amygdala, anterior insula, and dACC regions were chosen as a priori ROIs due to their mutual involvement in the following: (1) facial threat processing (Adolphs, 2002; Blasi et al., 2009; Fan et al., 2011); (2) susceptibility to sleep deprivation (Thomas et al., 2000; Goldstein et al.,
Table 3. Voxelwise whole-brain results for the ANOVA condition-threat interaction

\begin{tabular}{llrrrr}
\hline Region (BA) & $\begin{array}{l}\text { Cluster size } \\
\left(\mathrm{mm}^{3}\right)\end{array}$ & \multicolumn{1}{c}{$x$} & $y$ & $z$ & Zscore \\
\hline Insula (BA 13)-R & 1619 & 32 & 18 & -8 & 3.54 \\
Inferior frontal gyrus (BA 47)-R & & 32 & 18 & -18 & 3.34 \\
Inferior frontal gyrus (BA 47)-L & 744 & -38 & 20 & -8 & 3.36 \\
Precuneus (BA 19)-L & 306 & -38 & -78 & 36 & 3.35 \\
Insula (BA 13)-R & 175 & 36 & -12 & 20 & 3.29 \\
Inferior frontal gyrus (BA 47)-R & 263 & 42 & 20 & -16 & 3.26 \\
Inferior frontal gyrus (BA 47)-L & 175 & -50 & 18 & -4 & 3.23 \\
Anterior cingulate (BA 33)-L & 88 & -6 & 22 & 20 & 3.2 \\
\hline
\end{tabular}

Uncorrected $p<0.001,>10 \mathrm{~mm}^{3}$ contiguous cluster extent.

Table 4. Pearson correlation of discrimination activity across brain regions in sleeprested and sleep-deprived conditions

\begin{tabular}{lllllll}
\hline & L. amygdala & R. amygdala & dACC & L. insula & R. insula & Network \\
\hline Sleep-rested & & & & & & \\
L. amygdala & 1 & 0.38 & 0.27 & 0.15 & 0.06 & 0.41 \\
R. amygdala & & 1 & 0.37 & $\mathbf{0 . 5 1}$ & 0.35 & $\mathbf{0 . 6 8}$ \\
dACC & & 1 & $\mathbf{0 . 8 3}$ & $\mathbf{0 . 8 0}$ & $\mathbf{0 . 8 8}$ \\
L. insula & & & 1 & $\mathbf{0 . 8 6}$ & $\mathbf{0 . 9 2}$ \\
R. insula & & & & 1 & $\mathbf{0 . 8 0}$ \\
Network & & & & & 1 \\
Sleep-deprived & & & & & \\
L. amygdala & 1 & $\mathbf{0 . 5 1}$ & 0.44 & 0.32 & 0.46 & $\mathbf{0 . 6 1}$ \\
R. amygdala & & $\mathbf{0 . 6 7}$ & $\mathbf{0 . 4 8}$ & 0.37 & $\mathbf{0 . 7 3}$ \\
dACC & & 1 & $\mathbf{0 . 8 4}$ & $\mathbf{0 . 6 1}$ & $\mathbf{0 . 9 1}$ \\
L. insula & & & & 1 & $\mathbf{0 . 7 8}$ & $\mathbf{0 . 9 0}$ \\
R. insula & & & & & 1 & $\mathbf{0 . 8 0}$ \\
Network & & & & & & 1 \\
\hline
\end{tabular}

Significant correlations using a threshold of $p<0.05$ are displayed in bold font.

2013; Greer et al., 2013); and (3) affect-invoked autonomic regulation, especially the amygdala due to its afferent-efferent anatomical connectivity instigating cardiac control (Iwata et al., 1987; LeDoux et al., 1988; Critchley, 2005; Gray et al., 2012). Amygdala, anterior insula, and dACC ROIs were defined as $5 \mathrm{~mm}$ spheres centered on a set of peak activations reported in previous neuroimaging investigations of emotional face processing (MNI coordinates $[x, y, z]$ : left amygdala, $-19,-5,-17$; right amygdala, 22, $-1,-17$; left anterior insula, $-34,18,-10$; right anterior insula, 36, 20, -6; and dACC, -8, 24, 40; Blasi et al., 2009; Fan et al., 2011).

To test the hypothesis that the amount of REM sleep gamma activity observed on the sleep-rested night predicts the extent of the next-day discrimination activity to face stimuli within the viscerosensory affective network, individual REM gamma values were correlated with the average sleep-rested parameter estimates extracted from amygdala, anterior insula, and dACC for the threat discrimination contrast using a significance threshold of $p<0.05$ (performed in STATA 11; Poldrack and Mumford, 2009; Vul et al., 2009). To further localize the specificity of this association, a voxelwise analysis regressing the degree of REM gamma activity against the difference in threat versus nonthreat reactivity within the amygdala, anterior insula, and dACC was completed, again using an FEW-corrected threshold of $p<0.05$ within each mask. One participant was excluded from the spectral sleep components of the analyses as an outlier (spectral analysis values were $>3$ SD above the mean).

Similarly, to determine whether the cardiac threat discrimination profile predicted the viscerosensory threat discrimination in the sleep-rested and sleep-deprived sessions, the heart rate discrimination index (threatening $>$ not threatening at stimulus presentation) from each session was correlated with the extracted fMRI threat discrimination contrast estimates across each ROI (threatening $>$ not threatening), with a significance threshold of $p<0.05$. Complimentary voxelwise regression analyses using the cardiac discrimination index as a predictor were also completed (see above paragraph). Differences in correlation strengths across conditions were tested using the Fisher $r$ - to $Z$-transformed Pearson-Filon statistic (Raghunathan et al., 1996). 
Heart rate analysis. Interbeat intervals (IBIs) were calculated offline using MATLAB (http://www.billauer.co.il/peakdet.html) for the sleeprested and sleep-deprived sessions separately. Consistent with established values, an IBI $<400 \mathrm{~ms}$ or changes in IBIs $>200 \mathrm{~ms}$ from one interval to the next were considered artifacts and were not included in subsequent analyses (Steinhauer et al., 1992). Three participants were excluded from this portion of the analysis due to excessive cardiac artifacts. Heart rate in beats-per-minute was then calculated in $1 \mathrm{~s}$ bins (Graham, 1978). Artifact-free stimulus-evoked heart rate responses at the time of face stimulus presentation was created by subtracting the average of the $2 \mathrm{~s}$ prestimulus baseline from that of the $1 \mathrm{~s}$ after presentation. These heart rate measures were then entered into a repeatedmeasures condition (sleep-rested, sleep-deprived) $\times$ threat classification (threatening, not threatening) ANOVA performed using STATA 11 (StataCorp). Main effects and interactions were tested using a significance of $p<0.05$.

Sleep recordings. Sleep on the sleep-rested night was monitored in the laboratory with PSG sleep (23:00 h-7:30 h $\pm 30 \mathrm{~min}$ ) using a Grass Technologies Comet XL system. EEG was recorded at 19 standard locations conforming to the International 10-20 System (Jasper, 1958): FP1, FP2, F7, F3, FZ, F4, F8, T3, C3, CZ, C4, T4, T5, P3, PZ, P4, T6, O1, and $\mathrm{O} 2$. EOG was recorded at the right and left outer canthi (right superior; left inferior). EMG was recorded via three electrodes (one mental, two submental). Reference electrodes were recorded at both the left and right mastoid (A1, A2). Data were sampled first at $800 \mathrm{~Hz}$ by the amplifier digitized at $400 \mathrm{~Hz}$. All data were stored unfiltered (recovered frequency range of $0.1-100 \mathrm{~Hz}$ ) except for a $60 \mathrm{~Hz}$ notch filter to remove mainline noise. For recording only, each channel was referenced to a forehead scalp derivation.

Sleep scoring. Sleep staging was performed in accordance with standardized techniques (Rechtschaffen and Kales) using C3, C4, O1, O2, and right and left EOG and EMG channels. EEG and EOG were referenced to the contralateral mastoid, and filtered to $0.3-35 \mathrm{~Hz}$. EMG used a bipolar montage filtered to $10-70$ and $0.1-12 \mathrm{~Hz}$, respectively. Sleep was visually scored in 20 s epochs using the C3-A2 derivation according to standard criteria (Rechtschaffen and Kales). Sleep architecture values are reported in Table 1 and were consistent with previous cross-sectional normative values for this age group (Ohayon et al., 2004).

Spectral analyses. All EEG analyses were performed in MATLAB 7.5 (The MathWorks), including the add-in toolbox EEGLAB (http://sccn. ucsd.edu/eeglab/). Power spectral analysis of sleep EEG was performed according to previously published methods (van der Helm et al., 2011). Specifically, EEG channels were re-referenced to the average of the left and right mastoid (A1, A2), with high- and low-pass finite impulse response filtering at 0.5 and $80 \mathrm{~Hz}$, respectively. Artifacts were then visually rejected in $4 \mathrm{~s}$ epochs and removed from subsequent analyses. Moreover, because the spectral quantification of neural gamma activity can be unduly influenced by eye saccades during REM sleep, gamma activity was calculated only on saccade-free EEG time windows. Power spectral density was calculated with a fast Fourier transform (FFT) on each hamming-windowed $4 \mathrm{~s}$ epoch. FFT results were then sorted according to sleep stage and averaged for each respective stage. Power in bands was calculated by averaging across standard EEG frequency band ranges: $\delta$ $(0.8-4.6 \mathrm{~Hz}), \theta(4.6-8 \mathrm{~Hz}), \alpha(8-12 \mathrm{~Hz}), \sigma(12-15 \mathrm{~Hz}), \beta(18-30 \mathrm{~Hz})$, and $\gamma(30-40 \mathrm{~Hz})$ and log-transformed (John et al., 1980; Dijk et al., 1995; Buysse et al., 2008).

We focused a priori on REM sleep due to mounting evidence linking emotion processing to this brain state (Gujar et al., 2011; van der Helm et al., 2011; Goldstein and Walker, 2014). More specifically, analyses targeted EEG spectral gamma activity over prefrontal derivations during REM sleep based on previous fMRI evidence linking prefrontal REM sleep gamma with optimal affective brain function (van der Helm et al., 2011).

\section{Results}

Impact of sleep deprivation on behavioral threat ratings We first investigated whether sleep loss altered behavioral profiles of threat ratings. Sleep deprivation biased the behavioral (subjec-
A

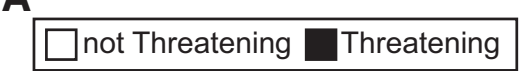

B
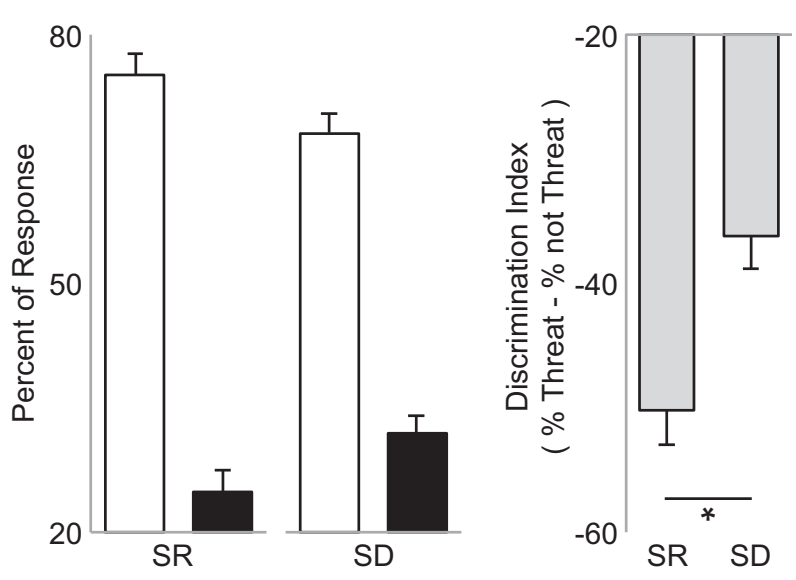

Figure 2. Behavioral results. $A$, Mean proportion of stimuli categorized as either threatening or not threatening in the sleep-rested (SR) and sleep-deprived (SD) conditions. B, Corresponding change in response tendency characterized as a threat discrimination index represented as the subtracted difference in the proportion of not threatening items relative to the portion of threatening items in the SR and SD conditions. A zero value represents equal number of stimuli assigned to threatening and not threatening categories, whereas a positive score represents a greater proportion of stimuli as rated as threatening relative to not threatening. A paired $t$ test demonstrated a significant increase in the proportion of faces rated as threatening in the SD condition compared with the SR condition $(t=2.36, p=0.03)$. Error bars indicate SEM. ${ }^{*} p<$ 0.05 .

tive) discrimination sensitivity of threatening from not threatening face stimuli (Fig. 2). Specifically, there was a shift in the profile of ratings after sleep deprivation, with significantly more faces categorized as threatening and significantly fewer as nonthreatening relative to the sleep-rested condition $(t=2.36, p=0.03)$. On average, participants rated $16.8 \pm 7.8$ stimuli as threatening (range: minimum: 3, maximum: 31 ) in the sleep-rested condition compared with $20.44 \pm 7.0$ of the stimuli when sleep deprived (range: minimum: 9, maximum: 31 ).

\section{Impact of sleep deprivation on central brain discrimination of threat}

We next sought to determine whether sleep impaired the neural discrimination of threatening from affiliative, nonthreatening facial cues in viscerosensory brain regions. A repeated-measures condition (sleep-rested, sleep-deprived) $\times$ emotion discrimination (threatening, not threatening) ANOVA revealed a significant interaction for activity in a priori cortical ROIs of the dACC and bilateral anterior insula (anterior insula left: $F=5.67, p=$ 0.03 ; right: $F=7.46, p=0.01$; voxelwise and ROI average results presented in Fig. 3$)$ and dACC $(F=7.04, p=0.02)$, but not in the subcortical ROI of the amygdala (left: $F=2.34, p=0.14$; right: $F=2.76, p=0.11$ ). To characterize this interaction, a discrimination index was derived for each ROI by subtracting the average activity to faces classified as not threatening from that of threatening. For this measure, a positive discrimination index indicates greater brain reactivity to threatening compared with affiliative, nonthreatening face stimuli (i.e., superior emotion dissociation), whereas a zero discrimination index would indicate identical reactivity to both affective faces stimuli alike (i.e., poor threat discrimination). Consistent with the experimental hypothesis, the anterior insula and dACC demonstrated activity that significantly (and positively) discriminated threat from nonthreatening 
A

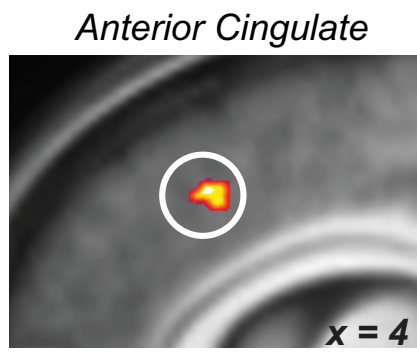

D

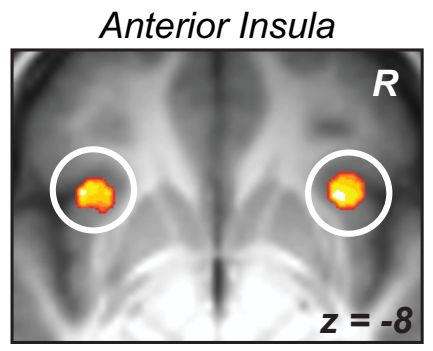

B

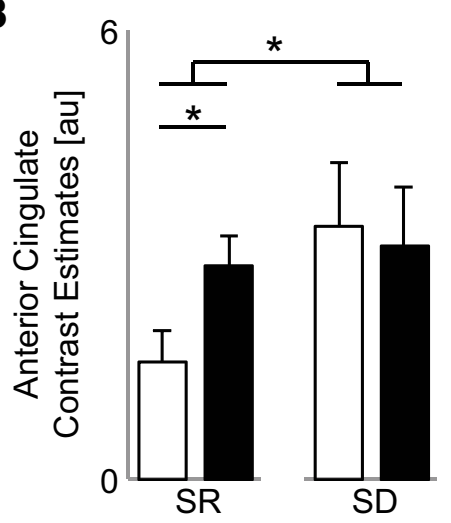

C

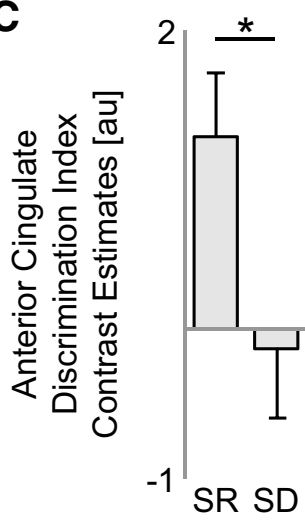

\section{$\square$ not Threatening $\square$ Threatening}

E

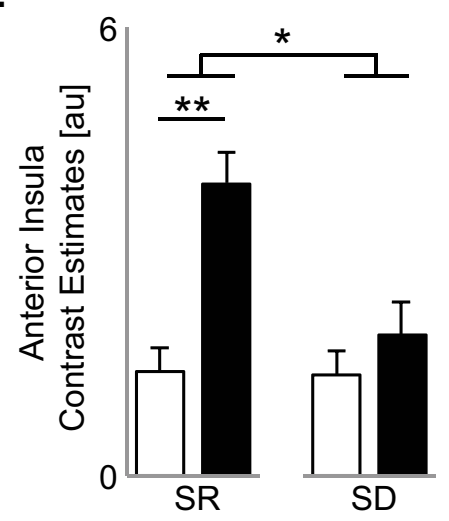

$\mathbf{F}$

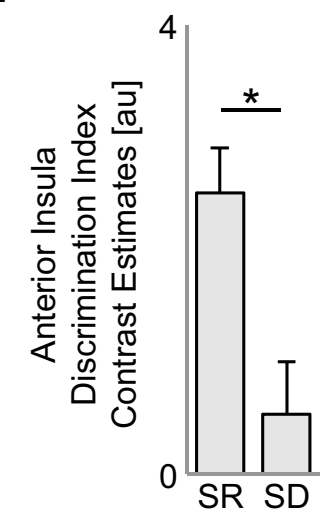

Figure 3. fMRI results. $A$, Brain maps displaying the condition: sleep deprivation (SD), sleep-rested (SR) $\times$ threat (threatening, not threatening) repeated-measures ANOVA interaction from the voxelwise ROI analysis in the $\mathrm{dACC}$ (peak MNI coordinates $[x, y, z]=6,26,42$ ) thresholded at FWE $p<0.05$ corrected for multiple comparisons. $\boldsymbol{B}$, Bar graph illustrating the difference in average parameter estimates across the $5 \mathrm{~mm}$ dACC ROI sphere mask and the average signal for each condition, respectively. In the sleep-rested condition, there was significantly greater activation across the $\mathrm{dACC} 5 \mathrm{~mm}$ ROI for threatening faces relative to nonthreatening. However, under conditions of sleep deprivation, the dACC reactivity did not differentiate between threatening and nonthreatening faces. C, Threat discrimination index represented as the subtracted difference of the average activity across the dACC $5 \mathrm{~mm}$ ROl for not threatening faces subtracted from the activity to threatening faces in the SD and SR conditions. A zero value represents equal activation to threatening and nonthreatening faces, whereas a positive score represents a greater activation to threatening relative to nonthreatening. $\boldsymbol{D}$, Brain maps displaying the condition $\times$ threat repeated-measures ANOVA interaction from the voxelwise ROl analysis in the anterior insula (peak MNI coordinates: left, $-38,20,-8$; right, 32, 18, -8. E, $\boldsymbol{F}$, Equivalent bar graphs as in $\boldsymbol{B}$ and $\boldsymbol{C}$ using the average of $5 \mathrm{~mm}$ spheres centered over bilateral anterior insula demonstrating strong threat discrimination ability in the rested condition and impaired threat responding in the deprived condition. Error bars indicate SEM. Within-region statistics: ${ }^{*} p<0.05,{ }^{* *} p<0.01$. Correlations between regions of the viscerosensory network discrimination activity are presented independently for the sleep-rested and sleep-deprived condition in Table 4 . Tables 2 and 3 display exploratory whole-brain activation differences for the threat $\times$ condition interaction, as well as threat reactivity in the sleep-rested session beyond our a priori ROls.

face stimuli in the sleep-rested state, yet no such significant (nearzero) discrimination was observed under sleep deprivation conditions (Fig. 3C,F). Moreover, this threat discrimination index was significantly different between conditions within both of these brain regions (all $t>2.38, p<0.04$ ).

Although neural interaction effects were not detected within the amygdala (unlike the viscerosensory cortical regions of the insula and dACC), it should be noted that the left amygdala expressed a significant positive threat discrimination index in the sleep-rested condition, eliciting greater activity to threatening compared with nonthreatening faces (left: $t=2.41, p=0.03$; right: $t=1.38, p=0.19)$. This sleep-rested profile of affective discrimination is congruent with previous reports describing the robust involvement of the left amygdala in processing threat (Fusar-Poli et al., 2009).

Together, these data indicate that sleep loss impairs the central brain's ability to disambiguate between varied social cues within viscerosensory cortical regions of the AACC and insula. Moreover, this loss of neural discrimination accuracy was accompanied by a shift in behavioral responding that resulted in biased, overestimation of threat relative to the sleeprested state and thus a reduced sensitivity to prosocial, affiliative cues.

\section{Impact of sleep deprivation on PNS threat discrimination}

We next sought to determine whether sleep deprivation additionally impaired the PNS discrimination of threat, focusing on changes in stimulus-evoked heart rate accelerations that reliably track affective face discrimination (van Honk et al., 2001; Critchley, 2005; Dalton et al., 2005; Gray et al., 2012). A condition (sleep-rested, sleep-deprived) $\times$ emotion discrimination (threatening, not threatening) repeated-measures ANOVA of elicited cardiac heart rate acceleration revealed a significant interaction effect $(F=5.78, p=0.03$; Fig. $4 A)$. This interaction was further reflected in differences in the cardiac discrimination index, which, as with changes in brain activity, was created by subtracting heart rate responses to nonthreatening faces from those of threatening faces. As predicted, a significant positive cardiac dis- 
A

\section{$\square$ not Threatening $\square$ Threatening}

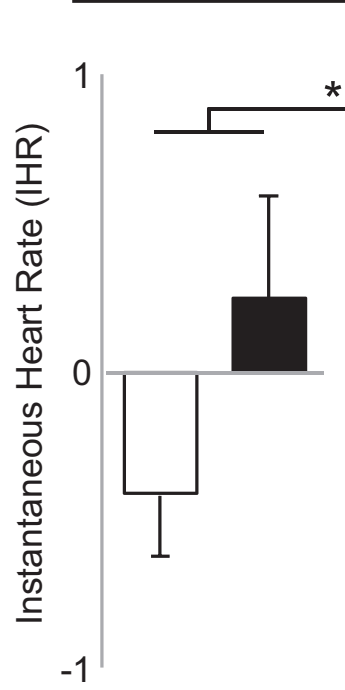

SR
B

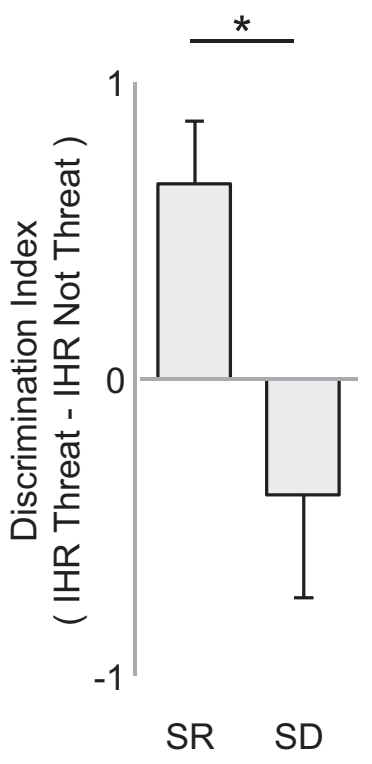

Figure 4. Cardiac threat-discrimination results. $\boldsymbol{A}$, Instantaneous heart rate response to threatening and not threatening face stimuli for sleep-rested (SR) and sleep-deprived (SD) conditions. B, Cardiac threat discrimination index represented as the subtracted difference of the cardiac response to nonthreatening faces subtracted from the cardiac response to threatening faces. A zero value represents equal cardiac responding to threatening and nonthreatening faces, whereas a positive score represents a greater activation to threatening relative to nonthreatening. Error bars indicate SEM. ${ }^{*} p<0.05$.

crimination index was expressed in the sleep-rested condition, reflecting greater acceleration responses to threatening relative to nonthreatening face stimuli. However, no significant cardiac threat discrimination signal was observed in the sleep deprivation condition (Fig. 4B), representing a blunted autonomic profile of sensitivity. Moreover, this cardiac threat discrimination index was significantly different between the two conditions $(t=$ $-2.40, p=0.03$; Fig. $4 B$ ). Therefore, in addition to disrupted central brain signaling, sleep deprivation further impaired the peripheral, autonomic-mediated, cardiac discrimination of threatening from affiliative social cues.

\section{Interaction between CNS and PNS threat discrimination}

Next, we tested the prediction that sleep deprivation impaired the degree of embodied affective processing, as evidenced by a degradation in the normal reciprocity between central brain and peripheral-cardiac activity during emotional discrimination.

Consistent with previous reports demonstrating right hemisphere associations in the embodied interaction between brain and autonomic threat responses (Critchley, 2005; Dalton et al., 2005; Critchley, 2009; Gray et al., 2012), regression analyses revealed significant predictive relationships between the peripheral (cardiac) and the central (brain) threat discrimination indices for two of the ROIs under sleep-rested conditions: the right amygdala $(r=0.64, p=0.01$; Fig. $5 A)$ and right anterior insula $(r=0.58, p=0.02$; Fig. $5 B)$, with a trend association in the dACC $(r=0.50, p=0.06$; Fig. $5 C)$. In contrast, no significant brainbody relationships were expressed in the sleep deprivation condition for any of the three ROIs (all $r<0.41 ; p>0.13$ ). Of the two brain areas significantly associated with cardiac discriminatory activity in the sleep-rested condition, the amygdala- a region with strong afferent-efferent anatomical reciprocity with cardiac control centers (Iwata et al., 1987; LeDoux et al., 1988; Critchley,
2005), also known to express sleep-statedependent relationships with autonomic cardiac control (Desseilles, 2006)-further demonstrated a significant difference in this brain-body association between the two conditions (right amygdala: $Z=$ $2.34, p=0.02$ ). For the insula, this betweencondition test of relationship strength was not significant (right insula: $Z=0.98, p=$ 0.32).

Therefore, beyond impairments separately identified within the PNS and CNS, these data suggest that sleep deprivation additionally degrades the coupled relationship between these systems that otherwise supports "embodied" sensation and discrimination of emotions (James, 1894; Craig, 2002; Critchley, 2005; Critchley and Harrison, 2013).

\section{Associations with REM sleep physiology}

Finally, and addressing the second hypothesis, we investigated whether the amount of REM sleep gamma EEG activity during the sleep-rested night predicted next-day interindividual differences of threat discrimination accuracy in the PNS and CNS. Consistent with this prediction, the amount of REM sleep gamma activity measured during the sleep-rested night significantly predicted the success of affective brain discrimination, such that individuals with less gamma activity tended to show superior threat discrimination activity (threatening $>$ not threatening) uniformly across these viscerosensory ROIs: the amygdala (left: $\beta=-0.53$, $t=-2.43, p=0.03$; Fig. $6 B$ ) and the anterior insula (left: $\beta=$ $-0.67, t=-3.49, p=0.003$; right: $\beta=-0.51, t=-2.31, p=$ 0.04; Fig. $6 C)$, and dACC $(\beta=-0.53, t=-2.43, p=0.03$; Fig. $6 D)$. Given the consistency of this relationship across ROIs, activity was averaged across the network as a whole, demonstrating equivalent results $(r=-0.61, p=0.009)$. Similar associations were also observed across central and posterior electrode derivations $(\mathrm{F} 3+\mathrm{F} 4, r=-0.53, p=0.03$; $\mathrm{C} 3+\mathrm{C} 4, r=-0.58, p=$ $0.01 ; \mathrm{P} 3+\mathrm{P} 4, r=-0.65, p=0.005)$ and did not differ in strength from prefrontal derivations (FP1 + FP2; Steiger's $Z$ test: all $Z<1.02, p>0.30$ ). These later findings suggest that observed relationship between viscerosensory brain activity and REM sleep gamma activity in prefrontal electrodes were unlikely to be the result of saccade-related artifact.

To determine the specificity of this REM sleep gamma relationship, a standard simultaneous multiple regression analysis was conducted. Here, associations between viscerosensory ROI threat discrimination activity and REM sleep gamma were investigated while also including non-REM (NREM) sleep gamma, slow-wave sleep (SWS) gamma, and SWS delta activity in the same statistical model. Results from this multiple regression analysis demonstrated that REM sleep gamma remained a significant predictor of next-day threat discrimination activity within the viscerosensory network while controlling for these other sleep physiology measures $(\beta=-0.65, t=-2.44, p=0.04)$. Further, no predictive relationships were observed for these additional sleep measures within this model (NREM gamma, SWS gamma, or SWS delta: all $p>0.72$ ). Moreover, whereas REM sleep 
A
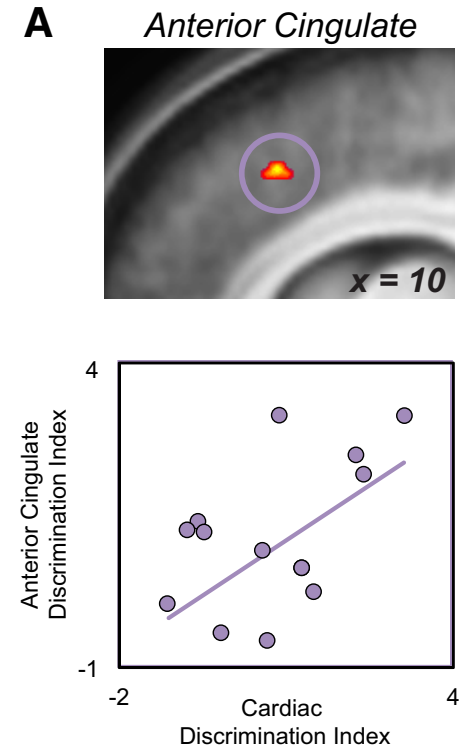

B
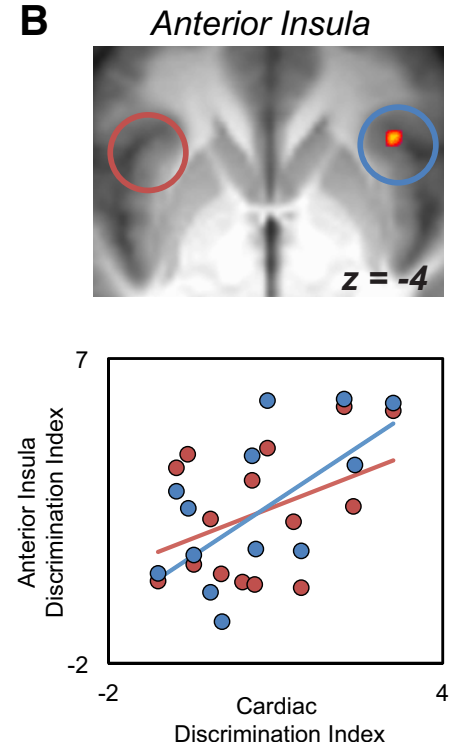

C
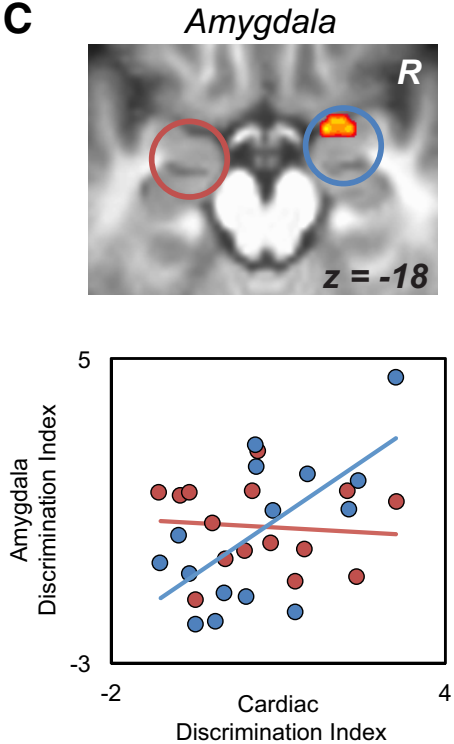

Figure 5. A, Brain maps displaying the voxelwise ROl regression between the cardiac discrimination index and the sleep-rested dACC discrimination ability (threatening $>$ not threatening contrast; peak MNI coordinates: 10, 22, 44 thresholded at FWE $p<0.05$ corrected for multiple comparisons). Scatterplot on far right displays this same relationship using the average parameter estimates across the $5 \mathrm{~mm}$ dorsal anterior cingulate ROI mask. Equivalent brain maps and regression plots for the anterior insula ( $\boldsymbol{B}$; peak MNI coordinates: right: $38,24,-4)$ and amygdala ( $\boldsymbol{C}$; peak MNI coordinates: $18,2,-16)$ Rols. No significant relationships were found for the left amygdala $(r=-0.09, p=0.75)$ or the left anterior insula $(r=0.42, p=0.12)$.

A

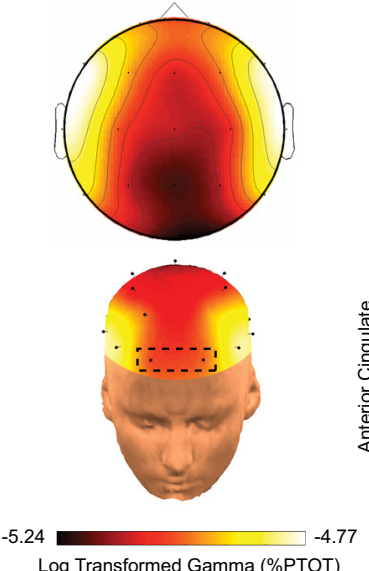

B Anterior Cingulate
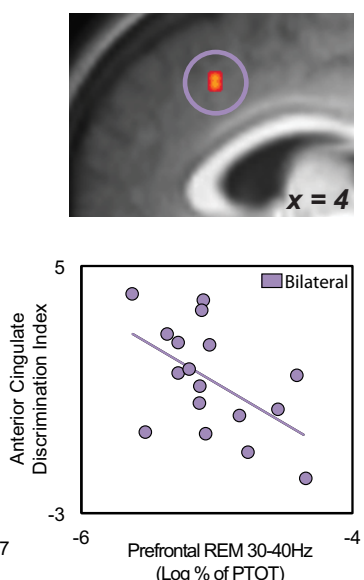
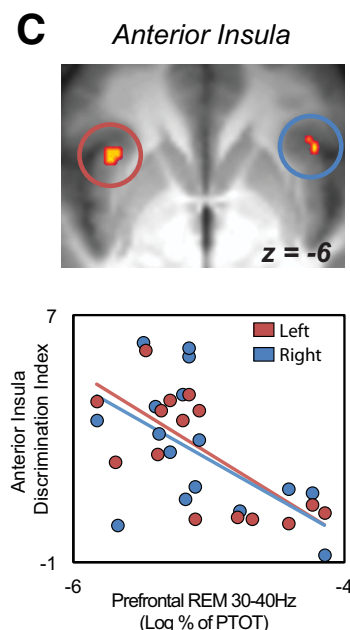

D Amygdala
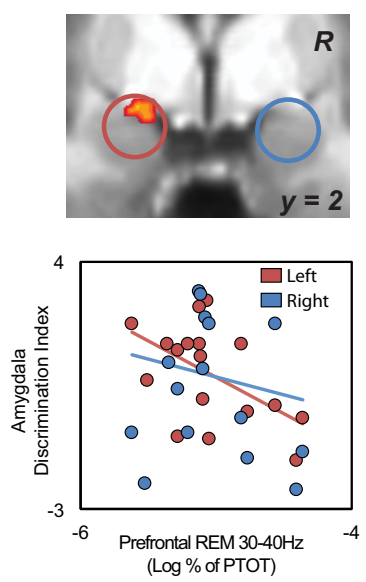

Figure 6. A, EEG topographic plot of log-transformed relative gamma activity $(30-40 \mathrm{~Hz})$ during REM sleep. $B$, Brain maps displaying the voxelwise ROI regression between relative REM gamma activity over frontal electrodes and the sleep-rested dACC discrimination ability (threatening $>$ not threatening contrast) (peak MNI coordinates: 4, 22, 40 thresholded at FWE $p<0.05$ corrected for multiple comparisons). Scatterplot on far right displays this same relationship using the average parameter estimates across the $5 \mathrm{~mm}$ dorsal anterior cingulate ROI mask. Equivalent brain maps and regression plots for the anterior insula ( $\boldsymbol{C}$; peak MNI coordinates: left, $-36,18,-10$; right, $40,22,-4)$ and amygdala $(\boldsymbol{D}$; peak MNI coordinates: $-20,0,-14)$ ROls.

gamma activity significantly and independently correlated with NREM gamma and SWS gamma activity (both $p<0.05$ ), and not SWS delta, none of these other spectral measures independently predicted next-day emotional brain discrimination accuracy (all $t<1.36, p>0.18$ ), unlike REM sleep gamma. This suggests that the effects observed between REM sleep gamma and emotional brain discrimination accuracy were not simply due to multicolinearity with other spectral sleep variables.

Inconsistent with our original prediction, however, there was no significant relationship observed between REM gamma activity and the cardiac index of threat discrimination $(r=-0.22 ; p=$ $0.44)$. Therefore, although the threat-discrimination activity of central brain and peripheral cardiac measures were significantly correlated with each other, the relationship between REM sleep physiology and next-day threat discrimination accuracy across individuals was specific to the central brain measures. Such data further establish that the influence of REM sleep upon the embodied threat response mechanism is transacted primarily at the level of brain rather than being under peripheral autonomic control.

\section{Discussion}

Sleep deprivation impairment of threat discrimination within the brain

The anterior insula and dACC contribute to affective decision making through integrating afferent viscerosensory body signals 
into second-order maps of the current body state (Critchley, 2005). These maps provide an ongoing homeostatic reference point for determining emotional state change (Craig, 2002) and instigating efferent autonomic motor-action control (Critchley, 2005). Only through such corporeal mapping can accurate discrimination of, and action responses to, affective signals be accomplished (Craig, 2002; Critchley, 2005).

Congruent with these proposals, both the anterior insula and dACC differentiated threatening from nonthreatening facial stimuli in the sleep-rested state. In contrast, no such discriminatory activity was observed after sleep deprivation, indicating a potential sleep-dependent deterioration of interoceptive sensitivity within homeostatic sensing networks of the brain (Craig, 2002). Such blunted sensitivity in the dACC and insula suggests an alteration in the affective homeostatic reference point caused by sleep loss, potentially related to inaccurate second-order mapping of the physiological condition of body viscera. This is further supported by the sleep deprivation increase in subjective threat bias observed in behavioral ratings.

This same neural framework may additionally offer a holistic brain-body account for previously reported mismatch inaccuracies in emotional recognition associated with sleep deprivation (Cote et al., 2014; Maccari et al., 2014). Considering the importance of accurate threat/safety-signal interpretation in determining appropriate social behaviors (Oosterhof and Todorov, 2008), this model may further explain reported associations between reduced sleep time and increased peer-related problems in youth (Hoedlmoser et al., 2010), decreased interpersonal functioning in adults (Killgore et al., 2008), and antisocial interactions (Sadeh et al., 1995).

Unlike the insula and AACC, no condition interaction was observed within the amygdala. This result differs from previous reports of amplified amygdala reactivity to emotional compared with neutral stimuli after sleep loss (Yoo et al., 2007; Gujar et al., 2011). However, this is not to suggest a lack of amygdala dysfunction in the current study. The amygdala expressly demonstrated a deterioration of the (normally) coupled association between brain and peripheral body (cardiac) signaling after sleep deprivation, which is addressed in detail below. Therefore, amygdala dysfunction after sleep loss appears to be consistent across a broad array of affective tasks. However, it is the functional role of the amygdala in specific emotional operations that may define the qualitative nature of this dysfunction (e.g., exaggerated amygdala (re)activity in the context of basic stimulus-response engagement; failed amygdala reciprocity with autonomic-body physiology in complex social evaluation).

\section{Sleep deprivation impairment of peripheral cardiac threat discrimination}

The mechanisms associated with differential cardiac responses to threatening relative to affiliative experiences are governed in part by vagal regulation of the heart rate (Porges, 2007). These autonomic heart rate changes provide differential afferent input to the CNS that aids in the discrimination of danger- from safetyrelevant stimuli and contexts. Fitting this profile of differential signaling, rapid heart rate elevations accurately separated threatening from nonthreatening cues in the sleep-rested condition. However, no such PNS differentiation was observed under sleepdeprived conditions, mirroring viscerosensory brain failures.

Building on the known mechanisms of affective body signaling, a reduction of the normally flexible vagal control of heart rate offers one parsimonious account of this blunted cardiac discrimination of social threat observed in the sleep-deprived state.
Supporting this proposal, basic cardiovascular research has demonstrated that acute sleep deprivation (Zhong et al., 2005; Sgoifo et al., 2006) and chronic poor sleep quality (Sato et al., 2014) disrupts the ability of the autonomic nervous system to inhibit sympathetic dominance. Moreover, sleep deprivation has been linked to reductions in vagal inhibition during emotional stressors (Sgoifo et al., 2006). Beyond the context of threat and safety, such a proposal raises the question of whether peripheral autonomic dysfunction represents a novel factor contributing to sleep-loss impairments in affective decision making (Killgore et al., 2007; Anderson and Dickinson, 2010) driven by inaccurate afferent body signals being centrally conveyed to the brain.

\section{Sleep deprivation and impaired reciprocity between CNS and PNS}

Although the central brain and peripheral cardiac systems each independently contribute to emotional processing, strong reciprocal coupling exists between these systems (James, 1894; Craig, 2002). It is from this "embodied" reciprocity, in which afferent information from the body feeds back to viscerosensory brain networks, that accurate feeling states are engendered that support the discrimination of emotional signals (Critchley, 2005).

Fitting embodied emotion-processing frameworks, the magnitude of threat discrimination responses in central brain (amygdala and insula) and peripheral cardiac measures were significantly coupled after a full night of sleep. However, no significant associations were identified in either region following sleep deprivation. Further, the strength of this association was significantly different between the sleep and sleep deprivation conditions within the amygdala. This unique dissociation is of special relevance considering the amygdala can instigate affect-related changes in body state by using well characterized efferent pathways that control autonomic cardiac activity (Iwata et al., 1987 1988, Critchley, 2005; de Abreu et al., 2015). Moreover, the amygdala receives ascending autonomic signals of arterial baroreceptor origin that contribute to the registration of affective value (Critchley et al., 2002; Makovac et al., 2015), further integrated by the anterior insula and dACC into second-order interoceptive maps (Critchley, 2005; Craig, 2010; Harrison et al., 2010). Such sleep-loss decoupling of brain-body reciprocity at the level of the amygdala may thus impair cardiac discrimination activity and impede the optimal use of already degraded afferent bodily information caused by sleep deprivation. Therefore, the amygdala offers one parsimonious central pathway (and dysfunctional hub) through which blunted cardiac (body) and cortical viscerosensory (brain) discrimination caused by sleep deprivation may be explained. Moreover, the consequences of such a "disembodied" state of affective processing may represent a holistic mechanism accounting for decreases in emotional expressiveness and empathy linked to sleep deprivation that normally depend on high-fidelity brain-body coupling (Killgore et al., 2008; McGlinchey et al., 2011; Minkel et al., 2011; Guadagni et al., 2014).

\section{REM sleep physiology and next-day emotion discrimination} On the sleep-rested night, REM sleep physiology significantly predicted next-day threat discrimination sensitivity within viscerosensory cortical and limbic subcortical regions. Previous findings have established a role for REM sleep gamma in overnight emotional memory depotentiation, dissipating amygdala responsivity the next morning to the same stimuli presented the night before (van der Helm et al., 2011). Our current findings suggest that the benefit of REM sleep physiology extends beyond 
emotional memory depotentiation and additionally supports a form of affective brain recalibration that enhances discrimination accuracy when evaluating novel, next-day social signals.

The gamma activity association can be interpreted within a recently described homeostatic model of REM sleep involving the recalibration of next-day affective brain function (Goldstein and Walker, 2014). Fostered by the characteristic reduction of noradrenergic tone during REM sleep (Siegel and Rogawski, 1988), the framework proposes a beneficial recalibration of sensitivity and specificity within an extended limbic network, optimally tuning next-day emotion signal processing. Using relative gamma EEG power as an indirect measure of noradrenergic tone (Keane et al., 1976; Berridge and Foote, 1991; Cape and Jones, 1998), we congruently demonstrate that lower REM gamma activity across individuals - potentially reflecting the greatest reduction in adrenergic tone-predicted superior next-day emotional discrimination accuracy within noradrenergic innervated regions of the dACC, anterior insula, and amygdala. Direct pharmacological manipulations in combination with functional imaging will nevertheless be required to offer causal validation. Moreover, how this state of low gamma activity and the associated emotional benefits it correlates with align with lucid dreaming states previously associated with higher-gamma activity (Voss et al., 2009) remains to be reconciled.

Finally, our findings should be appreciated within the context of certain limitations. First, the reduced number of trials rated as threatening may affect the robustness of the fMRI results. Although supplemental analyses demonstrated that the systematic removal of individuals with low trial numbers did not substantially change the results, future studies may seek to include greater numbers of trials to avoid potential bias caused by low trial sampling in select individuals. In addition, participants' sleep in the current paradigm was monitored with EEG on one night (during the sleep-rested session). Therefore, it is unknown whether the identified relationship between REM sleep physiology and emotional brain function reflects a stable, trait-like association or rather a state-dependent association that fluctuates from one night to the next. Subsequent studies assessing the same participants across multiple nights will help to discern between these possibilities.

Taken as a whole, the current study describes a disruption in the "embodied" CNS and PNS processing of threat and safety cues caused by sleep deprivation, impeding accurate discrimination of pro-social and antisocial signals. These impairments hold ecological relevance, particularly in contexts in which precise disambiguation of complex socio-emotional cues is critical but insufficient sleep is prevalent; for example, in members of the military, emergency service personnel, medical professionals, and new parents.

\section{References}

Adolphs R (2002) Neural systems for recognizing emotion. Curr Opin Neurobiol 12:169-177. CrossRef Medline

Adolphs R, Tranel D, Damasio AR (1998) The human amygdala in social judgment. Nature 393:470-474. CrossRef Medline

Agnew HW Jr, Webb WB, Williams RL (1966) The first night effect: an EEG study of sleep. Psychophysiology 2:263-266. CrossRef Medline

Anderson C, Dickinson DL (2010) Bargaining and trust: the effects of 36-h total sleep deprivation on socially interactive decisions. J Sleep Res 19: 54-63. CrossRef Medline

Berridge CW, Foote SL (1991) Effects of locus coeruleus activation on electroencephalographic activity in neocortex and hippocampus. J Neurosci 11:3135-3145. Medline

Blasi G, Hariri AR, Alce G, Taurisano P, Sambataro F, Das S, Bertolino A, Weinberger DR, Mattay VS (2009) Preferential amygdala reactivity to the negative assessment of neutral faces. Biol Psychiatry 66:847-853. CrossRef Medline

Buysse DJ, Reynolds CF 3rd, Monk TH, Berman SR, Kupfer DJ (1989) The Pittsburgh Sleep Quality Index: a new instrument for psychiatric practice and research. Psychiatry Res 28:193-213. CrossRef Medline

Buysse DJ, Germain A, Hall ML, Moul DE, Nofzinger EA, Begley A, Ehlers CL, Thompson W, Kupfer DJ (2008) EEG spectral analysis in primary insomnia: NREM period effects and sex differences. Sleep 31:1673-1682. Medline

Cape EG, Jones BE (1998) Differential modulation of high-frequency gamma-electroencephalogram activity and sleep-wake state by noradrenaline and serotonin microinjections into the region of cholinergic basalis neurons. J Neurosci 18:2653-2666. Medline

Cote KA, Mondloch CJ, Sergeeva V, Taylor M, Semplonius T (2014) Impact of total sleep deprivation on behavioural neural processing of emotionally expressive faces. Exp Brain Res 232:1429-1442. CrossRef Medline

Craig AD (2002) How do you feel? Interoception: the sense of the physiological condition of the body. Nat Rev Neurosci 3:655-666. CrossRef Medline

Craig AD (2010) The sentient self. Brain Struct Funct 214:563-577. CrossRef Medline

Critchley HD (2005) Neural mechanisms of autonomic, affective, and cognitive integration. J Comp Neurol 493:154-166. CrossRef Medline

Critchley HD (2009) Psychophysiology of neural, cognitive and affective integration: fMRI and autonomic indicants. Int J Psychophysiol 73: 88-94. CrossRef Medline

Critchley HD, Harrison NA (2013) Visceral influences on brain and behavior. Neuron 77:624-638. CrossRef Medline

Critchley HD, Mathias CJ, Dolan RJ (2002) Fear conditioning in humans: the influence of awareness and autonomic arousal on functional neuroanatomy. Neuron 33:653-663. CrossRef Medline

Dale AM (1999) Optimal experimental design for event-related fMRI. Hum Brain Mapp 8:109-114. Medline

Dalton KM, Kalin NH, Grist TM, Davidson RJ (2005) Neural-cardiac coupling in threat-evoked anxiety. J Cogn Neurosci 17:969-980. CrossRef Medline

de Abreu AR, Abreu AR, Santos LT, de Souza AA, da Silva LG Jr, Chianca DA Jr, de Menezes RC (2015) Amygdalar neuronal activity mediates the cardiovascular responses evoked from the dorsolateral periaqueductal gray in conscious rats. Neuroscience 284:737-750. CrossRef Medline

Desseilles M, Vu TD, Laureys S, Peigneux P, Degueldre C, Phillips C, Maquet $\mathrm{P}$ (2006) A prominent role for amygdaloid complexes in the variability in heart rate (VHR) during rapid eye movement (REM) sleep relative to wakefulness. Neuroimage 32:1008-1015. CrossRef Medline

Dijk DJ, Roth C, Landolt HP, Werth E, Aeppli M, Achermann P, Borbély AA (1995) Melatonin effect on daytime sleep in men: suppression of EEG low frequency activity and enhancement of spindle frequency activity. Neurosci Lett 201:13-16. CrossRef Medline

Fan J, Gu X, Liu X, Guise KG, Park Y, Martin L, de Marchena A, Tang CY, Minzenberg MJ, Hof PR (2011) Involvement of the anterior cingulate and frontoinsular cortices in rapid processing of salient facial emotional information. Neuroimage 54:2539-2546. CrossRef Medline

Friston KJ, Holmes AP, Worsley KJ, Poline J-P, Frith CD, Frackowiak RSJ (1994) Statistical parametric maps in functional imaging: a general linear approach. Hum Brain Mapp 2:189-210. CrossRef

Friston KJ, Glaser DE, Henson RN, Kiebel S, Phillips C, Ashburner J (2002) Classical and Bayesian inference in neuroimaging: applications. Neuroimage 16:484-512. CrossRef Medline

Fusar-Poli P, Placentino A, Carletti F, Landi P, Allen P, Surguladze S, Benedetti F, Abbamonte M, Gasparotti R, Barale F, Perez J, McGuire P, Politi P (2009) Functional atlas of emotional faces processing: a voxel-based meta-analysis of 105 functional magnetic resonance imaging studies. J Psychiatry Neurosci 34:418-432. Medline

Goldstein AN, Walker MP (2014) The role of sleep in emotional brain function. Annu Rev Clin Psychol 10:679-708. CrossRef Medline

Goldstein AN, Greer SM, Saletin JM, Harvey AG, Nitschke JB, Walker MP (2013) Tired and apprehensive: anxiety amplifies the impact of sleep loss on aversive brain anticipation. J Neurosci 33:10607-10615. CrossRef Medline

Graham FK (1978) Constraints on measuring heart rate and period sequentially through real and cardiac time. Psychophysiology 15:492-495. CrossRef Medline 
Gray MA, Beacher FD, Minati L, Nagai Y, Kemp AH, Harrison NA, Critchley HD (2012) Emotional appraisal is influenced by cardiac afferent information. Emotion 12:180-191. CrossRef Medline

Greer SM, Goldstein AN, Walker MP (2013) The impact of sleep deprivation on food desire in the human brain. Nat Commun 4:2259. Medline

Guadagni V, Burles F, Ferrara M, Iaria G (2014) The effects of sleep deprivation on emotional empathy. J Sleep Res 23:657-663. CrossRef Medline

Gujar N, Yoo SS, Hu P, Walker MP (2011) Sleep deprivation amplifies reactivity of brain reward networks, biasing the appraisal of positive emotional experiences. J Neurosci 31:4466-4474. CrossRef Medline

Harrison NA, Gray MA, Gianaros PJ, Critchley HD (2010) The embodiment of emotional feelings in the brain. J Neurosci 30:12878-12884. CrossRef Medline

Hoddes E, Zarcone V, Smythe H, Phillips R, Dement WC (1973) Quantification of sleepiness: a new approach. Psychophysiology 10:431-436. CrossRef Medline

Hoedlmoser K, Kloesch G, Wiater A, Schabus M (2010) Self-reported sleep patterns, sleep problems, and behavioral problems among school children aged 8-11 years. Somnologie (Berl) 14:23-31. CrossRef Medline

Iwata J, Chida K, LeDoux JE (1987) Cardiovascular responses elicited by stimulation of neurons in the central amygdaloid nucleus in awake but not anesthetized rats resemble conditioned emotional responses. Brain Res 418:183-188. CrossRef Medline

James W (1894) Physical basis of emotion. Psychol Rev 1:516-529.

Jasper HH (1958) The ten-twenty electrode system of the International Federation. Electroencephalogr Clin Neurophysiol Suppl 10:367-380. CrossRef

John ER, Ahn H, Prichep L, Trepetin M, Brown D, Kaye H (1980) Developmental equations for the electroencephalogram. Science 210:1255-1258. CrossRef Medline

Keane PE, Candy JM, Bradley PB (1976) The role of endogenous catecholamines in the regulation of electrocortical activity in the encephale isole cat. Electroencephalogr Clin Neurophysiol 41:561-570. CrossRef Medline

Killgore WD, Killgore DB, Day LM, Li C, Kamimori GH, Balkin TJ (2007) The effects of 53 hours of sleep deprivation on moral judgment. Sleep 30:345-352. Medline

Killgore WD, Kahn-Greene ET, Lipizzi EL, Newman RA, Kamimori GH, Balkin TJ (2008) Sleep deprivation reduces perceived emotional intelligence and constructive thinking skills. Sleep Med 9:517-526. CrossRef Medline

Kingshott RN, Douglas NJ (2000) The effect of in-laboratory polysomnography on sleep and objective daytime sleepiness. Sleep 23:1109-1113. Medline

LeDoux JE, Iwata J, Cicchetti P, Reis DJ (1988) Different projections of the central amygdaloid nucleus mediate autonomic and behavioral correlates of conditioned fear. J Neurosci 8:2517-2529. Medline

Maccari L, Martella D, Marotta A, Sebastiani M, Banaj N, Fuentes LJ, Casagrande M (2014) Effects of sleep loss on emotion recognition: a dissociation between face and word stimuli. Exp Brain Res 232:3147-3157. CrossRef Medline

Makovac E, Garfinkel SN, Bassi A, Basile B, Macaluso E, Cercignani M, Calcagnini G, Mattei E, Agalliu D, Cortelli P, Caltagirone C, Bozzali M, Critchley H (2015) Effect of parasympathetic stimulation on brain activity during appraisal of fearful expressions. Neuropsychopharmacology 40:1649-1658. CrossRef Medline

McGlinchey EL, Talbot LS, Chang KH, Kaplan KA, Dahl RE, Harvey AG (2011) The effect of sleep deprivation on vocal expression of emotion in adolescents and adults. Sleep 34:1233-1241. Medline

Minkel J, Htaik O, Banks S, Dinges D (2011) Emotional expressiveness in sleep-deprived healthy adults. Behav Sleep Med 9:5-14. CrossRef Medline

Ohayon MM, Carskadon MA, Guilleminault C, Vitiello MV (2004) Metaanalysis of quantitative sleep parameters from childhood to old age in healthy individuals: developing normative sleep values across the human lifespan. Sleep 27:1255-1273. Medline
Oosterhof NN, Todorov A (2008) The functional basis of face evaluation. Proc Natl Acad Sci U S A 105:11087-11092. CrossRef Medline

Pallesen S, Johnsen BH, Hansen A, Eid J, Thayer JF, Olsen T, Hugdahl K (2004) Sleep deprivation and hemispheric asymmetry for facial recognition reaction time and accuracy. Percept Motor Skills 98:1305-1314. Medline

Poldrack RA, Mumford JA (2009) Independence in ROI analysis: where is the voodoo? Soc Cogn Affect Neurosci 4:208-213. CrossRef Medline

Porges SW (2007) The polyvagal perspective. Biol Psychol 74:116-143. CrossRef Medline

Raghunathan TE, Rosenthal R, Rubin DB (1996) Comparing correlated but nonoverlapping correlations. Psychological Methods 1:178-183. CrossRef

Rechtschaffen A, Kales A (1968) A manual standardized terminology, techniques and scoring system for sleep stages of human subjects. Bethesda: U.S. Department of Health.

Sadeh A, Klitzke M, Anders TF, Acebo C (1995) Case study: sleep and aggressive behavior in a blind, retarded adolescent: a concomitant schedule disorder? J Am Acad Child Adolesc Psychiatry 34:820-824. CrossRef Medline

Said CP, Baron SG, Todorov A (2009) Nonlinear amygdala response to face trustworthiness: contributions of high and low spatial frequency information. J Cogn Neurosci 21:519-528. CrossRef Medline

Said CP, Dotsch R, Todorov A (2010) The amygdala and FFA track both social and non-social face dimensions. Neuropsychologia 48:3596-3605. CrossRef Medline

Sato M, Yasuhara Y, Tanioka T, Iwasa Y, Miyake M, Yasui T, Tomotake M, Kobayashi H, Locsin RC (2014) Measuring quality of sleep and autonomic nervous function in healthy Japanese women. Neuropsychiatr Dis Treat 10:89-96. Medline

Sgoifo A, Buwalda B, Roos M, Costoli T, Merati G, Meerlo P (2006) Effects of sleep deprivation on cardiac autonomic and pituitary-adrenocortical stress reactivity in rats. Psychoneuroendocrinology 31:197-208. CrossRef Medline

Siegel JM, Rogawski MA (1988) A function for REM sleep: regulation of noradrenergic receptor sensitivity. Brain Res 472:213-233. Medline

Steinhauer SR, Jennings JR, van Kammen DP, Zubin J (1992) Beat-by-beat cardiac responses in normals and schizophrenics to events varying in conditional probability. Psychophysiology 29:223-231. CrossRef Medline

Thomas M, Sing H, Belenky G, Holcomb H, Mayberg H, Dannals R, Wagner H, Thorne D, Popp K, Rowland L, Welsh A, Balwinski S, Redmond D (2000) Neural basis of alertness and cognitive performance impairments during sleepiness. I. Effects of $24 \mathrm{~h}$ of sleep deprivation on waking human regional brain activity. J Sleep Res 9:335-352. CrossRef Medline

van der Helm E, Gujar N, Walker MP (2010) Sleep deprivation impairs the accurate recognition of human emotions. Sleep 33:335-342. Medline

van der Helm E, Yao J, Dutt S, Rao V, Saletin JM, Walker MP (2011) REM sleep depotentiates amygdala activity to previous emotional experiences. Curr Biol 21:2029-2032. CrossRef Medline

van Honk J, Tuiten A, Hermans E, Putman P, Koppeschaar H, Thijssen J, Verbaten R, van Doornen L (2001) A single administration of testosterone induces cardiac accelerative responses to angry faces in healthy young women. Behav Neurosci 115:238-242. CrossRef Medline

Voss U, Holzmann R, Tuin I, Hobson JA (2009) Lucid dreaming: a state of consciousness with features of both waking and non-lucid dreaming. Sleep 32:1191-1200. Medline

Vul E, Harris C, Winkielman P, Pashler H (2009) Puzzlingly high correlations in fMRI studies of emotion, personality, and social cognition. Perspectives on Psychological Science 4:274-290. CrossRef

Yoo SS, Gujar N, Hu P, Jolesz FA, Walker MP (2007) The human emotional brain without sleep: a prefrontal amygdala disconnect. Curr Biol 17: R877-R878. CrossRef Medline

Zhong X, Hilton HJ, Gates GJ, Jelic S, Stern Y, Bartels MN, Demeersman RE, Basner RC (2005) Increased sympathetic and decreased parasympathetic cardiovascular modulation in normal humans with acute sleep deprivation. J Appl Physiol 98:2024-2032. CrossRef Medline 